\title{
Pressure fluctuations on the scour surface before prismatic pier
}

\author{
V.A. Voskoboinick \& A.V. Voskoboinick \\ Department of Hydrobionics and Boundary Layer Control, \\ Institute of Hydromechanics of the NAS of Ukraine, Kyiv, Ukraine \\ O.O. Areshkovych \\ Foundation Engineering Department, \\ Kyiv National University of Construction and Architecture, Kyiv, Ukraine \\ O.A. Voskoboinyk \\ Department of Technical Hydromechanics, \\ Institute of Hydromechanics of the NAS of Ukraine, Kyiv, Ukraine
}

\begin{abstract}
The results of experimental research of the wall-pressure fluctuation field acting on the scour surface upstream of the prismatic pier model are presented. Experiments were carried out in the hydraulic flume with an open water surface and sandy bed. The spatial and temporal characteristics of the field of pseudosound the wall-pressure fluctuation were determined on the equilibrium scour surface upstream of the prismatic pier model, as well as the sources of their generation. Two quasistable large-scale horseshoe vortex formations occurred inside the scour hole in front of the bluff body. The first of them were generated in the separation of the boundary layer with the front edge of the scour hole and it formed the upper slope of the scour. A second smaller horseshoe formation were formed by the interaction of the shear layer beyond the scour hole and the down flow along the front surface of the prismatic model and it formed the lower slope of the scour. The highest intensity and level of spectral components of the wall-pressure fluctuation occurred inside the scour hole upstream of the prismatic pier model.
\end{abstract}

\section{INTRODUCTION}

In the construction and operation of bridges, the installation of drilling towers and offshore wind turbine foundations, the flow causes soil erosion around foundational structures (Dargahi 1987, El Hassan et al. 2015, Nielsen et al. 2013). It is well known that the main mechanism governing the formation and the development of the scour includes down flow directed to the bottom on the front part of the pier, together with the formation of the horseshoe vortex system around the pier base and the wake vortices, which is separated from the pier strucute (AtaieAshtiani \& Aslani-Kordkandi 2012, Melville 1997, Voskoboinick et al. 2008). The interaction of the separated flow and the down flow in front of the pier, the horseshoe vortex system and the wake vortices lead to: soil scour around the pier, and dunes or ripples behind the pier. When the bed is flat, adverse pressure gradients slowing the approach flow cause flow separation near the bed. The incoming boundary layer beneath the bottom surface around the pier separates. The resulting necklace vortex develops within the separated region around the pier base. These vortices are a consequence of the reorganization of the boundary layer vorticity downstream of the flow separation line. The necklace vortices have the same sense of rotation as the vorticity in the upstream boundary layer. For most flow conditions, the location, size and intensity of the necklace vortices vary in time depending on the stage or phase of their formation and development (Escauriaza \& Sotiropoulos 2011, Kirkil \& Constantinescu 2015, Kirkil et al. 2008). Experimental and numerical studies of Ataie-Ashtiani \& Aslani-Kordkandi (2012), Das et al. (2013), Radice \& Tran (2012), Sheppard et al. (2014), Voskoboinick et al. (2014) show that evolution and strength of vortices around pier are affected by Reynolds number, as well as the level of freestream turbulence, the shape of the pier, the characteristics of the bed roughness, and the shape and size of the evolving scour hole. Different intensity and spectral filling the fields of the velocity, the shear stress and the wall pressure are generated on the scour surface under influence of the horseshoe vortex fomations and wake vortices (Voskoboinick 2008, Voskoboinick et al. 2009).

The purpose of this experimental work is to determine the spatial and temporal characteristics of the field of pseudosound wall pressure fluctuations on the equilibrium scour surface upstream of the prismatic pier model, as well as the sources of their generation.

\section{EXPERIMENTAL SETUP}

Experiments were carried out in the hydraulic flume with a length of $14 \mathrm{~m}$ and a width of $1.5 \mathrm{~m}$ with an open water surface by a depth of $H=(0.17-0.4) \mathrm{m}$ and 
sandy bed. The model prismatic pier with a length of $l=0.3 \mathrm{~m}$ and a width of $b=0.11 \mathrm{~m}$ was installed in a middle section of the flume. The pier was washed by water flow with a velocity from $U=0.15 \mathrm{~m} / \mathrm{s}$ to 0.6 $\mathrm{m} / \mathrm{s}$. For these flows and depths values, the Reynolds and the Froude numbers varied respectively $R e b=U b / v=(6000-67,000)$ and $F r=U / \sqrt{ } g H=(0.08$ $0.45)$, where $v$ - the kinematic viscosityof water; $g$ the free fall acceleration. Measurements of the scour depth, flow velocity and the wall pressure fluctuations were carried out simultaneously with the flow visualization by contrast substances and particles of neutral buoyancy. Wall-pressure fluctuation field acting on the scour surface were investigated by means of miniature (diameter sensitive surface 1.3 $\mathrm{mm}$ ) piezoelectric pressure fluctuation sensors, which measured sound and pseudosound pressure fluctuations (Voskoboinick et al. 2005, 2013). These sensors were flush-mounted with the streamlined surface in steady state of the scour hole (equilibrium scour) and did not perturb incoming flow. The sensor was mounted as follows (Fig. 1): sensor 1 was in front of scour hole at a distance of $0.2 b$ from the edge of the scour; sensor 2 was set in the middle of the upper slope of the sand deposition inside the scour hole; sensor 3 was on the ridge between the upper and lower slope of the sand deposition inside the scour hole and sensor 4 located at a distance of about $0.1 \mathrm{~b}$ in front of the prismatic model (in the greatest depth of the scour hole).

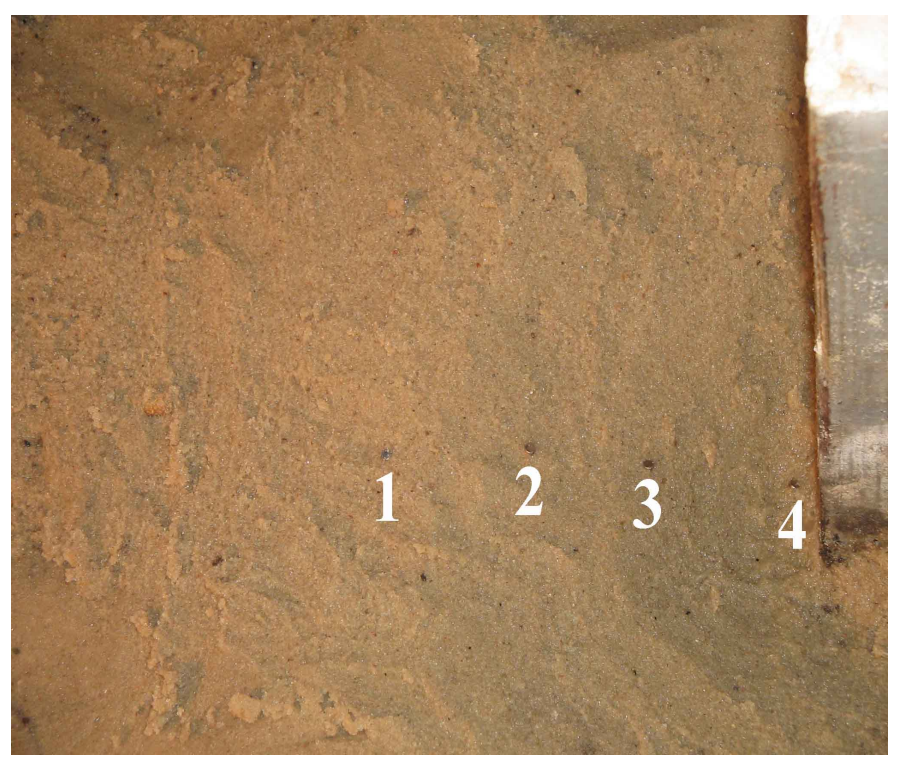

Figure 1. Wall-pressure fluctuation sensors on the streamlined surface of the scour hole before the prismatic pier model.

The electrical signals generated by the piezoceramic element sensors were equated to the levels of the wall pressure fluctuation at the measuring point, received at the preamplifiers. The signals were fed by the two-channel spectrum analyzer Brüel \& Kjær or through 16-channel analog-to-digital converters to the personal computers. The computer data were processed and analyzed using a fast Fourier transform algorithm by standard and specially developed programs and algorithms for statistical processing of the random processes. Sensors were calibrated and tested using absolute and relative methods. Measurement error of the intensity of the wall pressure fluctuation did not exceed $6 \%$ with the reliability 0.95 or $2 \sigma$, and the spectral components of the pressure fluctuation to $2 \mathrm{~dB}$ at the frequency range of $0.2 \mathrm{~Hz}$ to $800 \mathrm{~Hz}$.

\section{MEASUREMENT RESULTS}

Flow visualization around the prismatic pier and video analysis made it possible to evaluate spatial and temporal characteristics of horseshoe vortices generated inside the scour hole, as well as to watch their evolution. The formation of horseshoe vortices and their interaction with the streamlined surface leads to intensive washing-off of the contrast coating, which was used during visual research (Fig. 2).

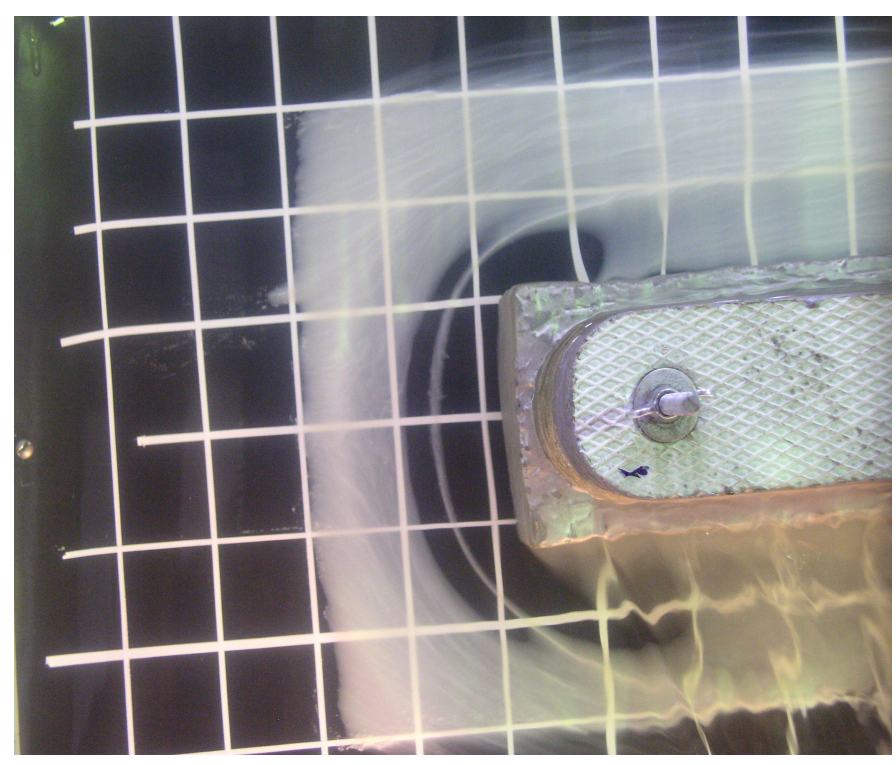

Figure 2. Washing-off of the contrast coating before the prismatic pier model on the rigid bottom.

When velocity near the bottom due to the vortex motion exceeds the critical transfer velocity of soil particles $V_{c}=6.19 H 1 / 6 d 501 / 3$ (Laursen 1963), the sand grains begin to move and around the prismatic pier form the scour as shown in figure 3 .

Over time, the depth of the scour hole increases and increases the height of the alluvium. At steady state, the scour formation that occurs after time $V c t / H>40,000$, shape and size of the scour hole remain practically constant, as shown schematically in perspective in figure 4. Research of Voskoboinick et al. (2006) has shown the maximum depth of the scour hole is observed at a distance of $0.25 b$ from the base of the prism, and the width of the hole is 2.5 depth of the scour. 


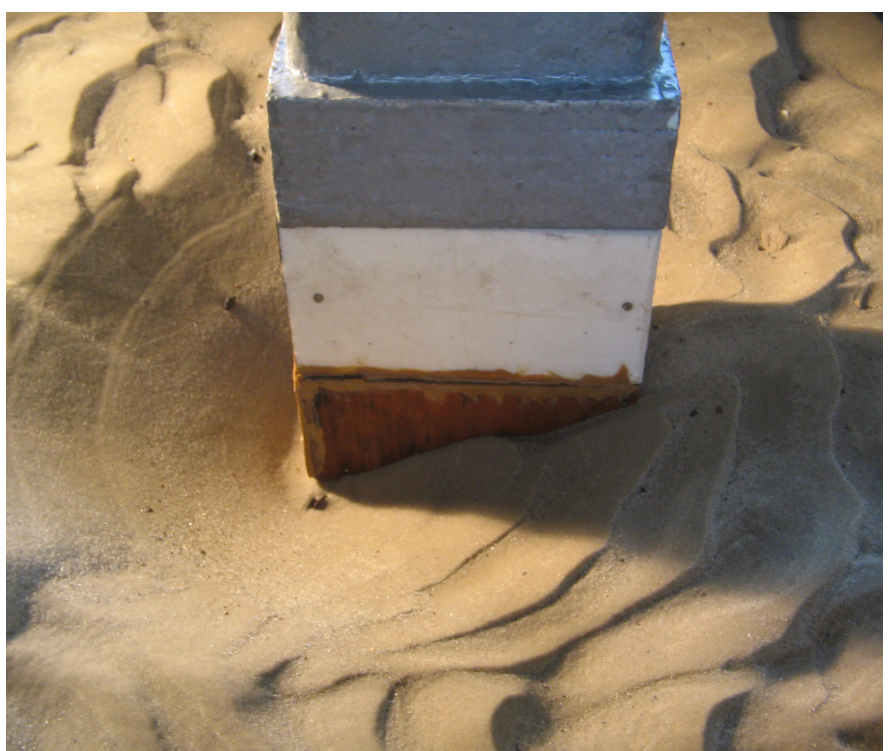

Figure 3. The scour hole and the alluvium of the sand soil about the prismatic pier model.
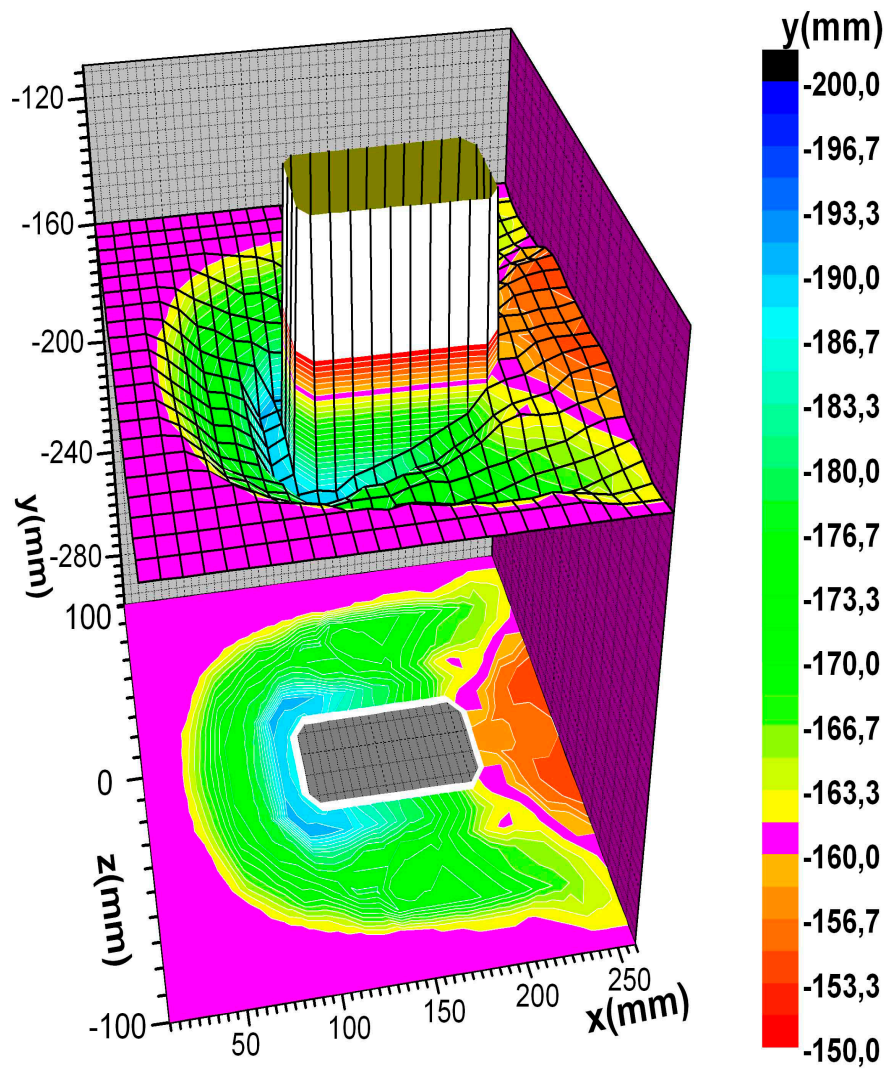

Figure 4. The scour hole and the alluvium of the sand soil about the prismatic pier model for $R_{b}=27,500$ and $F r=0.15$.

Profiles of the soil erosion upstream of the front wall of the prism have two characteristic regions with different angles of inclination (see Figs 3, 4).

They are caused by the formation of two systems of quasi-stable large-scale horseshoe vortex formations.

When the bluff body, regardless of its shape, is located on the rigid surface, then at the junction region in front of the base of the pier is generated a system of the horseshoe vortices schematically shown in figure 5. This system comprises two pairs of oppositely rotating vortices, that envelope the piers. These vortex formations oscillate in space around the pier and interact with each other and with the streamlined surface. Studies by Voskoboinick (2008) and Voskoboinick et al. (2009) regarding the velocity and pressure around a prismatic pier model have shown that the frequency of vortex oscillation ( 1 and 3 as per fig. 5) corresponds to Strouhal number $0.15 \ldots 0.20$.

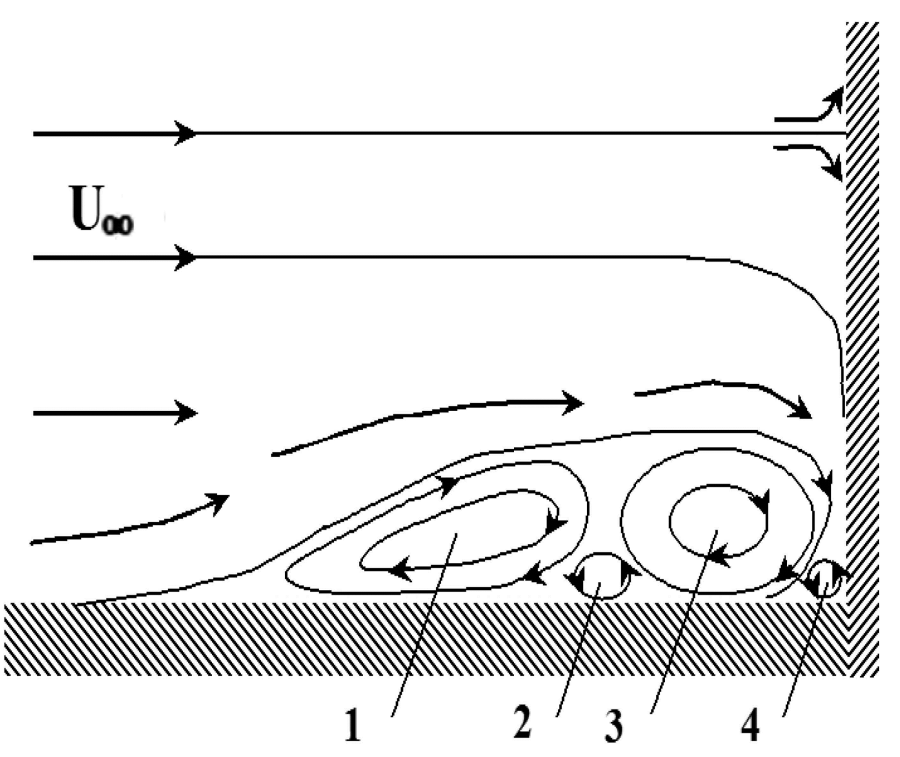

Figure 5. A sketch of the horseshoe vortical structures before the prismatic pier model on the rigid bottom.

It was found that soil erosion occurs first near the front edges of the prismatic model, due to the formation of the separated flow and vertical eddies in these edges. Then there is the erosion under the large-scale vortices, designated by the numbers 1 and 3 in figure 5. At the same time erosion under vortex number 3 is more intense. When the scour hole is increased, small-scale horseshoe vortex formations number 2 and number 4 are less visible and gradually degenerate. When the scour depth reaches the value of half the width of the prism, the quasistability horseshoe vortex system consists of two large-scale vortices, which are formed from vortices 1 and 3 shown in figure 5 .

A sketch of the equilibrium state of the soil erosion is shown in figure 6 . Inside the scour hole are the two large-scale horseshoe vortex formations, forming the scour and carrying sand particles from the front area of the prismatic pier to its aft area. Horseshoe vortices perform an oscillating movement, exchange energy with each other, often combined and broken down into smaller eddies. The vortex formation, located closer to the front wall of the prismatic pier base, has a smaller scale. It forms the largest soil erosion, which has a larger angle of slope of the sand deposition. In the interaction of the separated horseshoe vortex ( 1 in Fig. 6) with the eroding ground, the slope angle of the sand deposition in the 
scour hole is smaller and the scour under this vortex is shallower. Between the two cavities which are formed by the large-scale horseshoe systems, the sand deposition in the soil erosion profile is occurred (see Fig. 6). This sand deposition separates the two slopes of the scour hole and has quite clear outlines. However, the sand deposition oscillates inherently in space and corresponds to the frequencies of the vibrational motion of the vortex formations.

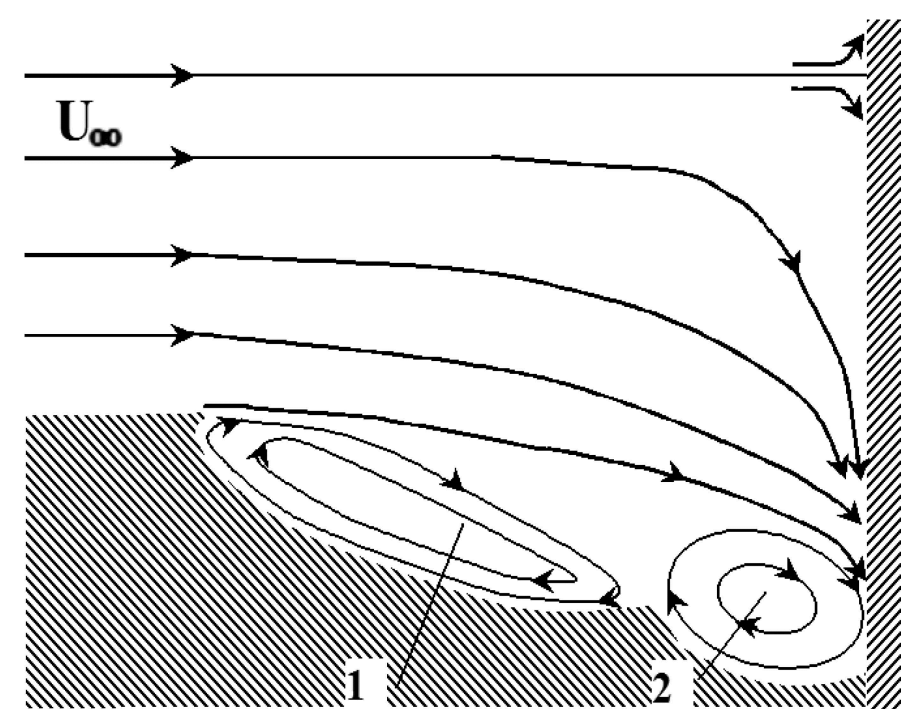

Figure 6. A sketch of the horseshoe vortical structures inside the scour hole before the prismatic pier model.

Depending on the location of the measurement points of the wall pressure fluctuation, the intensity of fluctuation and the spectral character are changed in accordance with the features of a vortex flow inside the scour hole.

In figure 7 the curve numbers correspond to the sensor numbers, as shown in figure 1. Upstream of the scour hole the wall pressure fluctuations are $0.01 q$, regardless of the Reynolds number. The intensity of the wall pressure fluctuations inside the scour hole increases with increasing Reynolds number. The lowest levels of the wall pressure fluctuations are observed in the area of formation of the upper slope of the scour, which is generated by a largescale horseshoe vortex structure (denoted as 1 in Fig. 6) due to separation of the boundary layer with the front edge of the scour hole. The maximum levels of the wall pressure fluctuations occur in the place where the down flow along the surface of the prism interacts with the eroding ground, forming the intense horseshoe vortex ( 2 in Fig. 6), which makes the lower slope of the scour hole. The intensity of the wall pressure fluctuations at the bottom of the scour hole is more than an order of magnitude greater than the intensity of the wall pressure fluctuations under separating horseshoe vortex, which forms the upper slope of the sand deposition in the scour hole before the prismatic pier model (see curves 4 and 2 in Fig. 7).

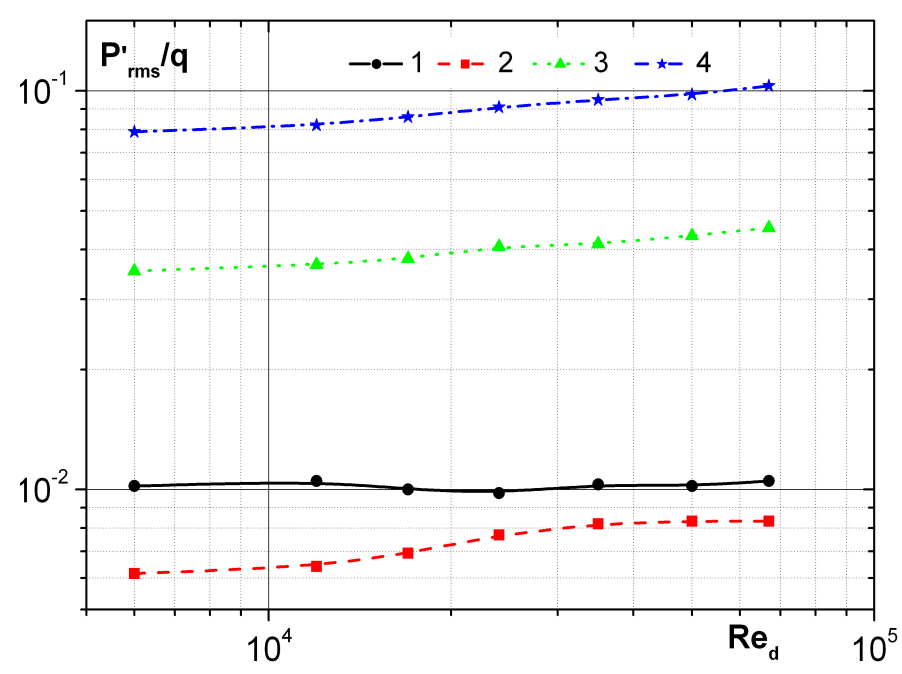

Figure 7. Intensity of the wall-pressure fluctuations on the streamlined surface before and inside of the scour hole.

The spectral power densities of the wall pressure fluctuations inside and near the scour hole in front of the prismatic pier model are shown in figures 8-10. Here, the levels of the spectra are shown in $\mathrm{dB}$ relative to the $2 \cdot 10-5 \mathrm{~Pa}$ depending on the dimensionless frequency in the form of $\omega^{*}=2 \pi f b / U$. Numbers of curves correspond to the numbers of sensors shown in figure 1 . For a velocity $0.18 \mathrm{~m} / \mathrm{s}$, which corresponds to the Reynolds number $R e b=20,500$ and the Froude number $F r=0.1$, the spectral dependences are shown in figure 8. Near prismatic model, the levels of the wall pressure fluctuations are highest throughout the investigated frequency range, and in the area of the forming of the horseshoe vortex formations with the separation region of the boundary layer the spectral levels are lowest. The difference between the spectral dependences is observed more than 20 dB. Maximum of the spectra takes place on the dimensionless frequency $\omega^{*} \approx 1.3$ in the region of the upper slope of the sand deposition inside the scour hole and $\omega^{* \approx} \approx 2.8$ near the prismatic model. In the region of the sensor number 3 (region of the sand deposition between the two slopes, as was shown by the visual research and profile measurement of the scour hole) the maximum values of the spectral power density of the wall pressure fluctuations are observed in both of these dimensionless frequencies. 


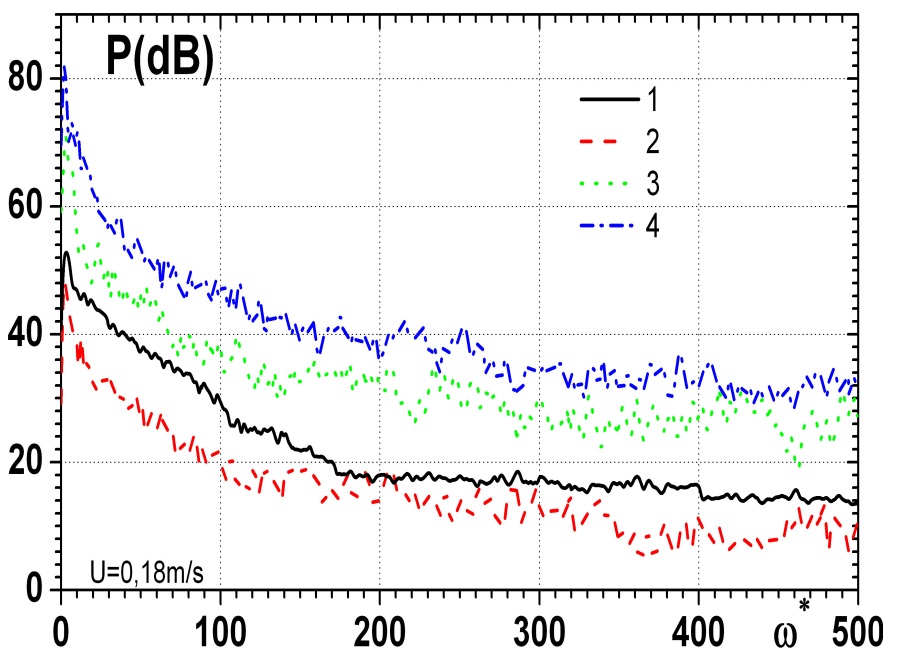

Figure 8 . The spectra of the wall-pressure fluctuations before and inside of the scour hole for $R_{b}=20,500$ and $F r=0.1$.

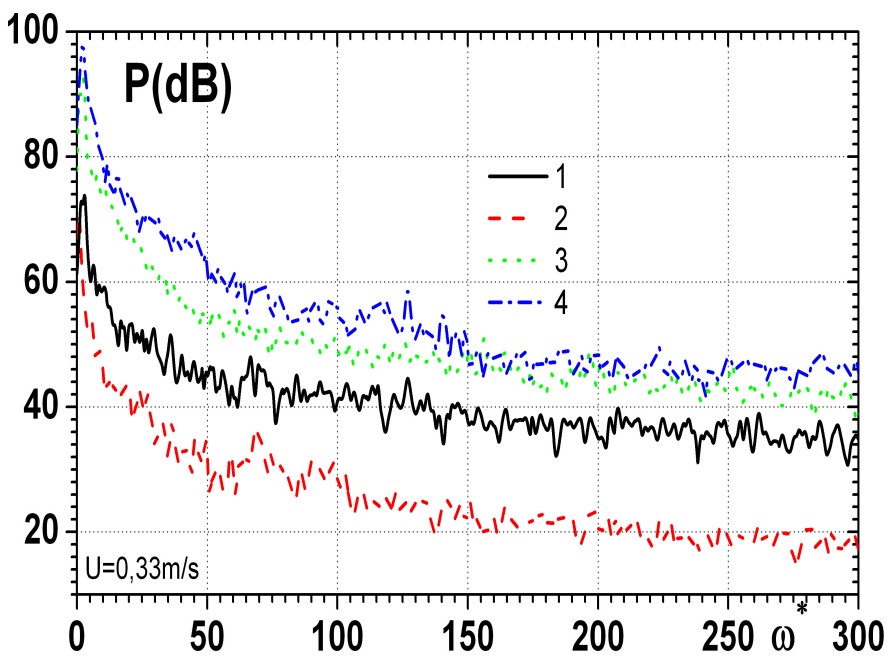

Figure 9. The spectra of the wall-pressure fluctuations before and inside of the scour hole for $R_{b}=50,200$ and $F r=0.25$.

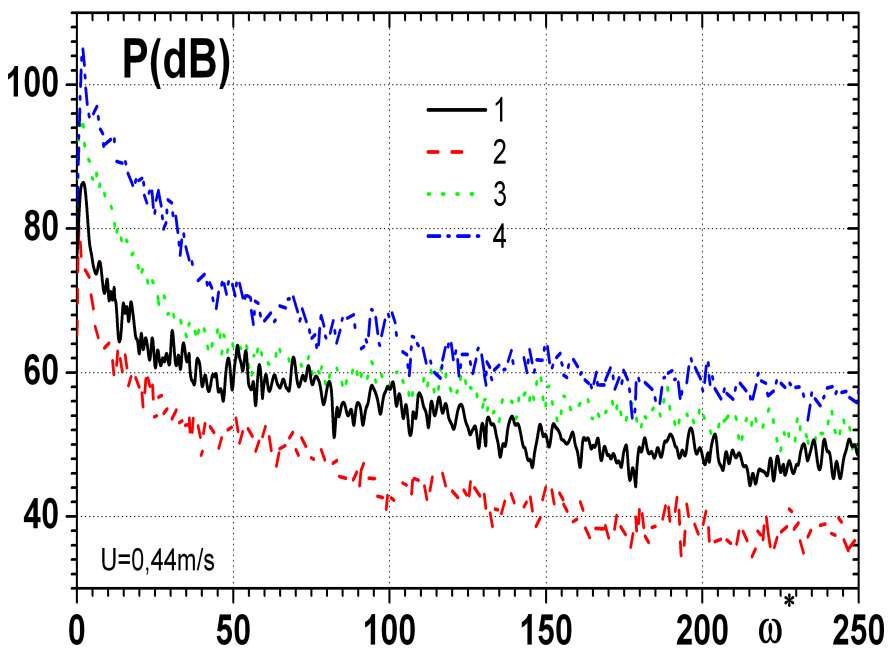

Figure 10. The spectra of the wall-pressure fluctuations before and inside of the scour hole for $\operatorname{Re}_{b}=37,600$ and $F r=0.19$.
The research results of the spectral dependences of the wall pressure fluctuations on the streamlined surface of the equilibrium scour hole before the prismatic pier model for the flow velocity of 0.33 $\mathrm{m} / \mathrm{s}(R e b=37,600$ and $F r=0.19)$ are shown in figure 9. For this flow mode, character of the spectra in the studied place positions remained unchanged. The highest levels are observed near the prism, and the minimum - in the region of the formation of the horseshoe vortex structure, located upstream. Maximum of the spectra occurred in the dimensionless frequencies $\omega^{*} \approx 0.76$ in the upper slope of the sand deposition inside the scour hole and $\omega^{*} \approx 2.28$ near the prismatic model.

When the flow velocity in the hydrodynamic channel increased to $0.44 \mathrm{~m} / \mathrm{s}$, which corresponds to the Reynolds number and the Froude number $R e b=50,200$ and $F r=0.25$, respectively, the character of the spectral dependences remained the same, as shown in figure 10. However, the maximum values of the spectral levels are observed in the dimensionless frequencies $\omega^{* \approx} \approx 0.57$ in the region of the upper slope of the sand deposition and $\omega^{*} \approx 1.71$ near the prismatic model. In the region of the sand deposition between the two horseshoe vortex systems, formed inside the scour hole before the prismatic pier model, the maxima of the spectra are observed on both of these frequencies.

So, inside the scour hole before the prismatic pier model are observed the high levels of the wall pressure fluctuations near the prism, where the down flow, propagating along the streamlined surface of the prismatic model to the bottom, interfaces with the eroding sandy soil. The maxima of spectral levels adjacent to the streamlined surface of the prism, occurred at the frequencies that are almost to 2-3 times higher than that in the region of the formation of the separated horseshoe vortex system. These frequencies, as shown by the visual research, correspond to the frequencies of the rotation of the largescale vortex formations that round the prismatic model (Voskoboinick 2008, Voskoboinick et al. 2009, 2014). The large-scale horseshoe vortex, that is formed from the circulating flow generated in the separation of the boundary layer with the front edge of the scour hole, has the dimensionless rotation frequency $S t=(0.1-0.2)$. Recall that this vortex forms the upper slope of the sand deposition inside the scour hole before the prismatic pier model, which is shown schematically in Fig. 7. Large-scale horseshoe vortex that is formed in the downstream slope of the sand deposition near the prismatic model is rotated with the dimensionless frequency $S t=(0.3-$ $0.5)$. Thus with increasing Reynolds number, the rotation frequencies of both the horseshoe vortices decrease. 


\section{CONCLUSIONS}

It was established that for the steady state flow, two quasistable large-scale horseshoe vortex formations occurred inside the scour hole in front of the bluff body in the form of the prismatic pier. The first of them is generated in the separation of the boundary layer with the front edge of the scour hole and it forms the upper slope of the scour. A second smaller horseshoe structure is formed by the interaction of the shear layer above the scour hole and the down flow along the front surface of the prismatic model and it forms the lower slope of the scour. The upper slope of the sand deposition has a smaller angle of the slope relative to the horizontal axis than the angle of the lower slope of the scour hole near the front surface of the prismatic pier base.

It was fixed that the highest intensity of the wall pressure fluctuations occur inside the scour hole upstream of the prismatic pier model where the down flow along the streamlined surface of the prism interacts with the eroding soil. Here, the pressure fluctuation is more than an order of magnitude greater than the pressure fluctuation at the horseshoe vortex system which is formed in the separation of the boundary layer at the front edge of the scour hole.

It was found that the highest levels of spectral components of the wall pressure fluctuations occurred near the base of the prism, and the lowest - on the surface of the upper slope of the sand deposition inside the scour hole. The difference of the spectral levels in these regions reaches $20 \mathrm{~dB}$ in the range of frequencies from $0.2 \mathrm{~Hz}$ to $500 \mathrm{~Hz}$. In spectral dependences was observed the discrete increases at the frequencies that corresponded to the rotation frequencies of the large-scale horseshoe vortices formed inside the scour hole. The rotation frequency of the horseshoe vortex near the prism base is about (2-3) times higher than in the upper slope of the sand deposition inside the scour hole. With increasing flow velocity (respectively, the Reynolds and Froude numbers), the dimensionless frequency of the rotation (Strouhal number) of the horseshoe vortices is decreased.

\section{REFERENCES}

Ataie-Ashtiani, B. \& Aslani-Kordkandi, A. 2012. Flow field around side-by-side piers with and without a scour hole. European J. Mechanics - B/Fluids 36(6): 152-166.

Dargahi, B. 1987. Flow field and local scouring around a cylinder. Stockholm: Royal Institute of Technology.

Das, S., Das, R. \& Mazumdar, A. 2013. Comparison of characteristics of horseshoe vortex at circular and square piers. Research Journal of Applied Sciences, Engineering and Technology 17(5): 4373-4387.
El Hassan, M., Bourgeois, J. \&·Martinuzzi, R. 2015. Boundary layer effect on the vortex shedding of wall- mounted rectangular cylinder. Exp Fluids 56:33-1-19.

Escauriaza, C. \& Sotiropoulos, F. 2011. Lagrangian model of bed-load transport in turbulent junction flows. J. Fluid Mech. 666: 36-76.

Kirkil, G. \& Constantinescu, G. 2015. Effects of cylinder Reynolds number on the turbulent horseshoe vortex system and near wake of a surface-mounted circular cylinder. Phys. Fluids 27: 075102-1-25.

Kirkil, G., Constantinescu, G. \& Ettema, R. 2008. Coherent structures in the flow field around a circular cylinder with scour hole. J. Hydraulic Eng. 134(5): 572-587.

Laursen, E.M. 1963. An analysis of relief bridge scour. J. Hydraulic Division 89: 93-118.

Melville, B.W. 1997. Pier and abutment scour: Integrated approach. J. Hydraulic Eng. 123(2): 125-136.

Nielsen, A.W., Liu, X., Sumer, B. M. \& Fredsoe, J. 2013. Flow and bed shear stresses in scour protections around a pile in a current. Coastal Engineering 72(2): 20-38.

Radice, A. \& Tran, C.K. 2012. Study of sediment motion in scour hole of a circular pier. J. Hydraulic Research. 50(1): 44-51.

Sheppard, D.M., Melville, B. \& Demir, H. 2014. Evaluation of existing equations for local scour at bridge piers. J. Hydraul. Eng. 140: 14-23.

Voskoboinick, A.A., Voskoboinick, A.V., Voskoboinick, V.A., Marchenko, A.G. \& Nikishov, V.I. 2006. Local bed scour with an arrangement of two bridges supports located in the wake one after another. Applied Hydromechanics 8(3): 1626.

Voskoboinick, A.A., Voskoboinick, A.V., Voskoboinick, V.A. \& Nikishov, V.I. 2014. Pressure fluctuations on the scour surface. Applied hydromechanics 16(2): 27-35.

Voskoboinick, A.V., Voskoboinick, V.A. \& Voskoboinick, A.A. 2008. Junction flow of three-row pile grillage on a flat plate. Part 1. Horseshoe vortex generation. Applied hydromechanics 10(3): 28-39.

Voskoboinick, A.V., Voskoboinick, V.A. \& Voskoboinick, A.A. 2009. Space-time correlations and spectra of velocity fluctuations of a junction flow beneath three-row cylindrical groups. Problems of Water-supply, Overflow and Hydraulics 12: 165-177.

Voskoboinick, V., Kornev, N. \& Turnow, J. 2013. Study of near wall coherent flow structures on dimpled surfaces using unsteady pressure measurements. Flow Turbulence Combust. 90(4): 709-722.

Voskoboinick, V.A. 2008. Velocity field statistical characteristics of the junction flow around the three-row pile grillage. Bulletin of Donetsk University, Series A: Natural Sciences 2: 130-137.

Voskoboinick, V.A., Grinchenko, V.T. \& Makarenkov, A.P. 2005. Pseudo-sound behind an obstacle on a cylinder in axial flow. Intern. J. Fluid Mech. 32(4): 488-510. 